\title{
Both-Ways science education: Place and context
}

\begin{tabular}{|c|c|}
\hline Joel Rioux & Gregory Smith \\
Batchelor Institute of Indigenous Tertiary & Charles Darwin University \\
Education & gregory.smith@cdu.edu.au \\
\hline joel.rioux@batchelor.edu.au & \\
\hline
\end{tabular}

Keywords: Indigenous preservice teachers; science teaching; Both-Ways; pedagogical discourse

\begin{abstract}
This paper presents a Both-Ways place-based science education initiative, which situates Indigenous and western science knowledge traditions together as official curriculum knowledge, within a Bachelor of Education science education unit. This program is delivered in-situ to preservice teachers who work as Aboriginal Teaching Assistants in school classrooms. The program, known as Growing Our Own, is established in Indigenous communities in the Northern Territory (NT). This initiative has engaged Indigenous preservice teachers in border-crossing pedagogical practices as a way to recognise the legitimate use of the Indigenous concepts of place. It has also contextualised the teaching of school science as described in the Australian curriculum. This Both-Ways approach privileges the voices and knowledge of local Indigenous peoples and creates a bridge to the curriculum of science in a placebased contextually relevant methodological manner. Such modifications realise a meaningful cultural and place contextualization, which values and enables border-crossing between local Indigenous science knowledge, language and western science. The paper presents pedagogical discourses of place-based and contextual approaches in five NT Indigenous communities to demonstrate how the teaching of science has been reconceptualised. The authors and the preservice teachers use Indigenous perspectives intertwined with the science of the Australian curriculum. Such approaches have provided meaningful border-crossing opportunities for preservice teachers in the Growing Our Own program.
\end{abstract}

\section{Introduction}

This paper presents a Both-Ways (B-W) narrative by two non-Indigenous university lecturers working in communities with Aboriginal (Indigenous) ${ }^{1}$ preservice teachers employed as Aboriginal Teaching Assistants in their community's school. Both lecturers have previously taught in schools with Indigenous students: one in North West Queensland; and the other in Central Queensland. However, both were "strangers in a strange land" (Heinlein, 1961), a metaphor from the science fiction novel of the same name, where a human raised on Mars arrives on Earth and takes a journey to adapt to, and understand, earth humans and their culture. This metaphor is at the centre of a B-W journey in which preservice teachers and their lecturers, cross borders through the legitimised use of Indigenous place.

These lecturers promote a space for a B-W crossing of borders through the reconceptualisation of aspects of the Australian science curriculum. Such a space, a third space (Bhabha, 1994), a space of hybrid borders where curriculum reconceptualisation exists, will necessarily include already forged alliances between Indigenous preservice teachers, young children, community members, and Elders. This is a pedagogic discourse of recontextualisation in which Indigenous knowledge of place is legitimised, using preservice teacher and community meanings related to their local context of place and science, through the pedagogic device.

$1 \quad$ Aboriginal from the Latin meaning from the beginning and other such Eurocentric words are used because we understand that there is no Indigenous word that refers to all Aboriginal people in Australia. The more appropriate terminologies are the Indigenous Australian people/s, Aboriginal people/s, Aboriginal person, Torres Strait Islander people/s, or Torres Strait Islander person. The more appropriate terms stress the humanity of Aboriginal and Torres Strait Islander people (Flinders University, 1996). In this paper, we use the term Indigenous. 


\section{Both-ways place-based science education}

The overarching aim of this paper is to present particular aspects of the border-crossing pedagogic device objects, which were developed through collaborative discourse between two university lecturers and Aboriginal preservice teachers. This paper presents a B-W place-based science education initiative that situates Indigenous and western science knowledge traditions together as official curriculum knowledge within a Bachelor of Education science education unit.

B-W education (sometimes referred to as Two-Ways ${ }^{2}$ ) is an approach that "brings together Indigenous Australian traditions of knowledge and Western academic disciplinary positions and cultural contexts" (Batchelor Institute, 2007, p. 8). The B-W approach privileges the voices and knowledge of local Indigenous peoples to create a bridge to the curriculum of science in a place- based contextually relevant methodological approach. In this narrative, we use the term B-W science education. The use of this term provides a focus for lecturer and preservice teacher to engage in pedagogical discourse that integrates both science and Indigenous knowledge traditions.

The Indigenous preservice education students provide the cross-border pedagogic examples in this paper. They are employed as Aboriginal Teaching Assistants (ATA) and work in school classrooms located in remote Indigenous communities. They are enrolled in the Bachelor of Education, where their journey crosses the border from ATA to Registered Teacher as part of the Growing Our Own (GOO) program delivered in-situ to these Indigenous preservice teachers. The crossing journey is constituted in the socio-cultural knowledge and practice of an ATA; this knowledge is legitimated in, and by, their culture. The crossing can be seen in the different complexities of responsibility and interactions within the school, and the status of Indigenous science knowledge in the official school curriculum documents. In sum, their learning journey involves crossing the border from the ATA's culture into the teacher's culture.

\section{Border crossing}

The concept of borders and border-crossing brings notions of specialised fields of knowledge bound within the social divisions of labour within the school (Bernstein, 2000). The preservice teachers have specialised knowledge fields that have been defined in language, culture and community. This border is evident in all the remote participant schools where the ATA preservice teachers work.

Borders are also evident between the official school science knowledge represented in the Australian curriculum, and local place-based Indigenous knowledge. The culture of the Australian science curriculum represents science with little or no engagement in Indigenous knowledges, let alone placebased knowledge of the saltwater, freshwater and desert Indigenous peoples of Australia. Science, in the participant schools, represents a strong classification and science borders are insulated from other school disciplines and from everyday community knowledge.

Through the preservice teacher's pedagogical discourse, there was a recognition that Indigenous placebased knowledge and western science knowledge could develop a more permeable border by using local contexts. Such border permeability developed through the preservice teachers' realisation and recognition that "their place knowledge" could be legitimised in a recontextualised curriculum. This ATA discourse provided a cultural crossing between the world of school science and Indigenous world views, thus creating a more inclusive meaning to school science within the community. The cultural crossing presented in this paper demonstrates a B-W learning for preservice teachers and lecturers in connection with the living landscapes of the community.

2 Both-Ways and Two-Ways both consider their origins in a story recollected by McConvell (1982), in which a Gurindji (NT) man, Pincher Nyurrmiyarri, advocated 'two-way school' rather than 'one-way school' or 'only kartiya (European) way', heard by McConvell as early as 1975. 


\section{Pedagogy of place}

The construct, 'Pedagogy of Place', is implicitly associated with Indigenous culture, Indigenous perspectives in science, and B-W pedagogical discourse. Barnhardt and Kawagley (2008) advocated that successful science education, curriculum and programming for Indigenous people should involve Pedagogy of Place or "learning through culture" (p. 113). Such a view of place and culture provided a pedagogical discourse that moved "from teaching about local culture to teaching through the culture as students learn about the immediate places they inhabit and their connection to the larger world within which they will make a life for themselves" (Barnhardt \& Kawagley, 2008, p. 113). Culturally responsive pedagogies in science education using "place" have been gaining momentum with Indigenous people around the world.

In 2011, Aikenhead and Michell reported that recognition of place-based knowledge and contexts provided an opportunity for the coexistence model of Indigenous ways of knowing and the western- based school science curriculum. Studies have found that a sense of place is "a key factor to learning science in the Indigenous context. In fact, the significance of place is becoming a predominant theme in Indigenous science education" (Sutherland \& Swayze, 2013, p. 179). They also suggested that creating relevant learning environments using Indigenous local place in science will contribute to student engagement, motivation and validation of their knowledge. Ezeife (2003) and McKinley (2005) argued for science education in Indigenous communities all over the world to be relevant, and not dominated by pedagogical devices devoid of the place or local environmental knowledge. Ezeife (2003) also acknowledged the lack of direct relevance of knowledge to Aboriginal peoples' place and, as Sarra (2011) emphasised, the place is people's immediate environment, to which they are deeply attached psychologically, physically, and spiritually.

Increasing collaboration with local community members (Schott, 2005), and developing a sense of place, is pedagogically critical for the discourse of Growing Our Own preservice teachers. Educators need local Indigenous people as resource people in their classrooms (Linkson, 1999; Michie \& Linkson, 1999; Michie, 2002) and they also need to embrace Indigenous leadership (Hyde, Carpenter, \& Conway, 2014; Sarra, 2007). Rennie (2006) corroborated and encouraged educators to use community resources to complement those based in the school. Local Indigenous peoples from remote communities increase the variety of stimuli and sources of information, and thus increase the likelihood that preservice teachers will want to engage in more meaningful learning. Growing Our Own preservice teachers are daughters, sons, mothers, fathers, aunties and uncles who are integral to the community and their classroom. Such positioning enhances opportunities for the pedagogic discourse of curriculum recontextualisation.

Bernstein (2000) called such legitimation processes "pedagogic recontextualisation" in which new meanings of the official curriculum knowledge emerge, relevant to the community. It is also important to understand that place-based knowledge is not useable for everyone; that cultural rules apply. Cajete (2000) cautioned and indicated that "particular places are endowed with special energy that may be used, but must be protected" ( $p$. 70). Therefore, an inbuilt spiritual curriculum construct for us as lecturers, involved considering the status of the intellectual knowledge tradition of the Australian curriculum constructs. Our border crossing represents a reconceptualised curriculum, partly invisible, valuing preservice teacher Indigenous knowledge traditions, while incorporating the realms of western science, yet challenging aspects of the western science cloak of objectivism.

\section{Method: Narrative with case studies}

This paper presents five case studies from our lecturing experience with Indigenous tertiary students using the B-W approach. Each of the case studies considers the potential conflicts through engagement with the two knowledge traditions. A narrative inquiry methodology is used. According to Connelly and Clandinin (1990), "The study of narrative...is the study of the ways humans experience the world" (p. 1). This method is particularly useful when based in the lives and work of teachers (Goodson, 2008; Webster \& Mertova, 2007). Each of the unique case studies is a narrative, or story, about how the author implemented the B-W approach in their classroom. The case studies also reflect on student participation in the relevant approach. The narratives provide a foundation for the ensuing discussion, which focuses 
on successful strategies for engaging with western and Indigenous constructs in science, and on gaining a deep understanding about how each group of students' wrestles with the issue of B-W knowledge.

\section{Pedagogic recontextualisations from the Northern Territory, Australia: legitimisation of place}

The preservice teachers in the following case studies work in the classrooms in one of five remote Indigenous community schools in the NT where the Growing Our Own program is being delivered. The preservice teachers' work is also associated with the border crossings previously outlined. As bordercrossers on a journey, preservice teachers recognise the importance of using place-based and contextual pedagogical approaches in their teaching of science teaching.

This section of the study presents examples of a pedagogical discourse around place-based Indigenous perspectives in the science curriculum delivery. Here, there is a shifting of a strongly classified science discourse towards a B-W discourse of legitimisation and validation of Indigenous science knowledges. The preservice teachers present Indigenous perspectives that historically preceded western views because, to them, culture matters. For the lecturers, there was, and continues to be, a deliberate post-colonially intended shift towards a pedagogical discourse of local traditional contextual approaches, using local ways of living and knowing first. The Indigenous values, their traditional perspectives, and knowledges were acknowledged as a major contributor to the unit delivery. We first aspired to be presenting a culturally affirming environment for the Indigenous preservice teachers. Western school science was re-contextualised in a B-W approach to provide a border crossing, which connected the Indigenous and non-Indigenous worlds in a shared knowledge understanding and common language. The following examples provide a snap-shot view of a place- based B-W approach of curriculum recontextualisation.

\section{The Tiwi Islands context: Local traditional sugarbag (bush honey or yingwati)}

Locally significant, traditional sugarbag (honey or yingwati) collection occurs near bodies of water on the Tiwi Islands, located 80 kilometres north of Darwin. The collection happens during the season known as Kumunupunari, or the dry season of fire and smoke (June-July-August). The yingwati is emblematic, not only because it provides nature's best organic chewing gum-a yellow part of the beehive can be chewed-but it also plays a strong role in the wellbeing of the community. Preservice teachers aspire to teach Tiwi children where to locate local native bees and yingwati. The Tiwi peoples usually prepare damper-an early European settlers' bread, tea, and the yingwati delicacy is accompanied by roasted possum, to add flavour.

Yingwati is a living thing for the local peoples and has spiritual significance (Moria, personal communication, November 2016). For instance, after collecting it, the person is not allowed to wash their hands in the nearby lake because the Rainbow Serpent could come out and harm them (Mammy, personal communication, November 2016). Also, preservice teachers would not discuss the taboo subject of Pukamani stories related to bees with the Tiwi children. The gatherer would always ask permission of Elder ancestors to collect yingwati as they entered the bush and prepared to cut the tree for honey collection. If this protocol was not followed, the community would be disgruntled and resentful. Moria advised that "We also need to discuss with the students how to use the stem of the fan palm leaf to collect the precious liquid gold resource" (Moria, personal communication, November 2016). The tool required for this cultural activity is known as the pandanus spoon.

The role that bees play in their colony, and throughout the Tiwi landscape, is also important for Tiwi people. For example, larger bees are the colony's protectors and must be respected (Batchel, personal communication, November 2016). Yingwati is only consumed on the spot, in the bush where people find it, otherwise it may bring community discontent and misfortunes to the collector (Batchel, 2016). The Tiwi tradition also stipulates that if the collector does not consume all of the discovered honey in one sitting, the beehive must be covered with certain types of leaves in order to protect and keep it fresh for weeks (Mammy, personal communication, November 2016). Yingwati is placed on the skin as an armband, as part of a custom during ceremonies; it is also used on the face of a teenager as they become men (Motram, personal communication, November 2016). The iconic yingwati enlivens border-crossing and, 
as Bernstein (1990) suggested, using this pedagogic discourse as a recontextualising principle, brings together Indigenous place, mathematics and science knowledge of the Australian curriculum.

\section{Australian curriculum content descriptors and elaborations: Tiwi Islands (open- investigations)}

Local and national science curricula content descriptors work in a complementary fashion in a B-W approach on the Tiwi islands. The approach values the local Indigenous preservice teachers' knowledges and their Tiwi bush curriculum includes the locally iconic subject, Tiwi Yingwati. This subject relates to the 'content descriptors and elaborations' contained in the local place-based curriculum, while also being a culturally significant object to the Tiwi peoples, as discussed above. In the western science curriculum 'content descriptions and elaborations' define what is to be taught and what students are expected to learn. There is a distinction between the local Indigenous content descriptors, which are mandatory to pass on to the next generation, and the western content descriptors and elaborations of the Australian curriculum, which "are non-mandatory components but are provided to suggest contexts through which to explore the core Science content in both depth and breadth" (Australian Curriculum, Assessment and Reporting Authority, 2018, p. 7).

Primary school teachers of Tiwi children may want to conduct a place-based, local, open investigation (work scientifically) to reach some of the outcomes of the western curriculum. This could be achieved by collecting data, visually presenting data and analysing results related to local sugarbag (yingwati). Planning and conducting are favourable Inquiry skills to promote investigative scientific skills from the Australian curriculum. In Year 5, for instance, the teacher is encouraged to cultivate inquiry skills by helping children to decide variables to be changed and measured in fair tests; and observe, measure, and record data with accuracy using digital technologies, as appropriate (ACSIS087). Two elaborations could be possible when preservice teachers are working out bush with the children: (1) discussing in groups how investigations can be made as fair as possible, and (2) using tools to accurately measure objects and events in investigation and exploring which tools provide the most accurate measurements.

The Australian curriculum has four sub-strands in Science. The Chemical sciences strand proposes one Year 5 content descriptor: Solids, liquids and gases have different observable properties and behave in different ways (ACSSU077). One elaboration of this descriptor explores the way solids, liquids and gases change under different situations such as heating and cooling. Another sub-strand (Year 5 Biological sciences) recommends one content descriptor: Living things have structural features and adaptations that help them to survive in their environment; and the supporting elaboration suggests: Describing and listing adaptations of living things suited for particular Australian environments (ACSSU043).

Inquiry questions might include:

- Why has the beehive been attached to a particular local tree species for many millennia?

- How do the Tiwi bees compare with the larger and more aggressive European bees?

- What are the characteristics of each type of bee?

- Investigate the recent invasion of Asian bees in the Top End (NT) and discover why they have adapted to the Top End climate.

The next section presents outcomes of the preservice teachers' recontextualisations of the science and mathematics curriculum contents as part of the reconceptualisation discourse.

\section{Details of Tiwi open investigation plan using yingwati}

A cohort of eight Indigenous Tiwi preservice teachers were introduced to the open investigation planner (working scientifically), which was an opportunity to engage in the pedagogic discourse to select the problem and the methods of investigation. It was suggested that an open investigation could be conducted with children out bush based on western constructs such as viscosity, or a study of liquids' properties, or characteristics and movement of particles. A 'dirt wall' was the most appropriate method for children and 
preservice teachers working out bush and would allow them to explicate the western constructs of fluidity and viscosity, for example during honey races, then students could brainstorm variables. This method was chosen rather than using the 'word wall'.

Our initial question for investigation was about working scientifically with the velocity of liquids: the rate of the flows. The question: Would traditional yingwati travel faster than European honey in a race? The prediction: yingwati is watery, runny and will be faster than the European honey because the particles don't hold to each other so tightly. Elders would accompany the Tiwi preservice teachers and children for the honey gathering excursion. There were a considerable amount of possibilities in terms of variables, and in terms of extension work for investigations. For example: What about altering the temperature of the honey, as a potential variable to investigate? Can heating yingwati on the fire in a billy help it race even faster against the unheated European honey? What if the European honey is heated instead of yinwati? Would it arrive first at the finishing line? What about a race with both honeys heated or not heated at all?

For the Tiwi people in the Top End of Australia, the crocodile is culturally significant, and the consumption of the reptile's tail is considered a delicacy. Knowing this about the target group of students, preservice teachers on Tiwi Islands were encouraged to use the mnemonic C-M-S (Croc, Moves, Silently) with Tiwi children to help them learn the types of variables. $C$ means Change only one thing-Independent variable. $\mathrm{M}$ means Measure/Observe what would the change affect? - Dependent variable. S means Same: Which variables will you control? -Controlled variables. Only one variable is changed at a time to make it a fair test, as required in the accredited university course materials.

C: change one variable: heating. Place yingwati in two containers but only heat one of the containers of yingwati.

M: measure the time in seconds travelled by the liquids over a 1 metre distance on a recycled plank of wood with a rock under one end to produce a slope, and observe which liquid wins.

S: same distance travelled (one metre), same amount of honey (thirty $\mathrm{mL}$ ) partaking in the race, same container to pour the honey from, same departure line, same arrival line, same distance each time between the two liquids racing at starting time, same honey (yingwati), same angle or slant of the board, and so on.

\section{Both-Ways example from Wadeye: science and mathematics}

Thuykem is a culturally significant place for the Wadeye community located 420 kilometres south west of Darwin. Thuykem is a flat top hill rising above the flood plains. The locals also refer to it as "Airforce Hill" because, during World War 2, this place was used as a Royal Australian Air Force Radar Station due to the commanding view of the Bonaparte Gulf and the Timor Sea in Northern Australia. Thuykem is a culturally significant place that presented a real-world opportunity for a problem-solving investigation that crossed the disciplines of science and mathematics. The university curriculum for the Bachelor of Education included the requirement for a Fermi problem solving approach within the primary mathematics curriculum. Fermi problems are based on the selection of real-world context- specific problems that engage students in estimation and rough calculation with the collected data (Peter-Koop, 2005). The science curriculum required the use of Science Understanding, Science Inquiry and Science as a Human Endeavour within the sub-strands of Chemistry and Biology. The lecturer perceived a space for B-W crossing of borders through the reconceptualisation of aspects of the Australian Science curriculum.

A cohort of five Indigenous preservice teachers were presented with an opportunity to engage in the pedagogic discourse to select the problem and the methods of investigation. Bernstein (1990) provided a working definition of the pedagogic discourse, as a "recontextualizing principle which selectively appropriates, relocates, refocuses, and relates other discourses to constitute its own order and orderings" (p. 184). In this example, the pedagogic discourse brought together Indigenous place, mathematics and science knowledge.

The collaborative process between the students provided context and direction. Thuykem was the 
starting point and the Gas Plant Road Cycad forest was the end. These places were chosen as they were significant to the community. Permissions for biology field work were granted from the Elders responsible for the land. The investigation began as a comparative quadrat study, but with further discussion on the purpose of the study, the project morphed into a business venture: a cycad forest was surveyed to determine the viability of selling cycads to Darwin. The following excerpts from the student's work illustrate the approach used in this study.

Figure 1: Map of plant distribution data, Thuykem: $100 \mathrm{~m}^{2}$

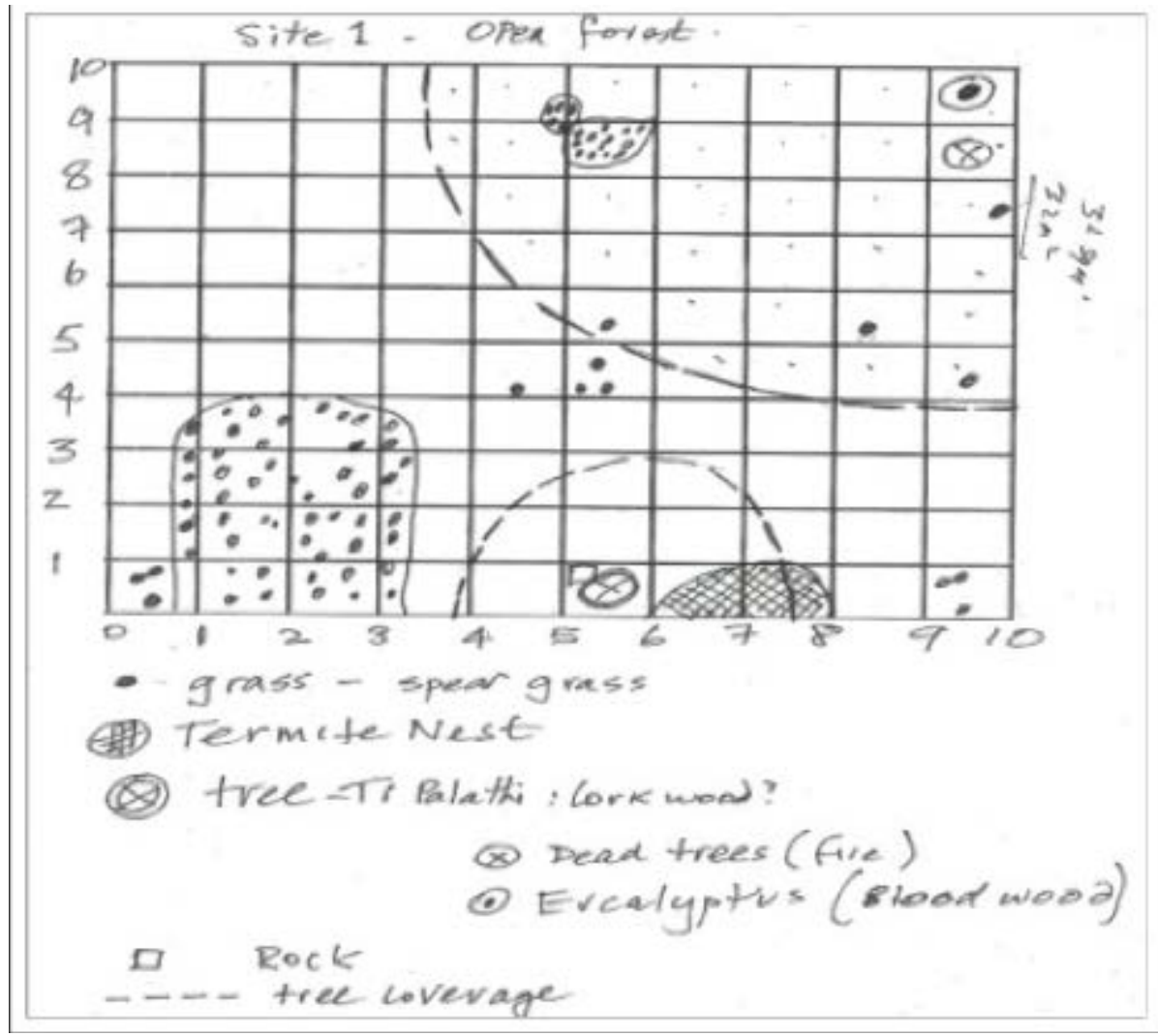

Source: Student A permission granted

Figure 1 represents the plant life in the area and the different trees such as the Corkwood (Thay Palathi), Eucalyptus (Bloodwood), and dead trees that looked like Corkwood. There was also plenty of spear grass and a rock (Student A). Table 1 below indicates the estimated area covered by living and non-living things in the 100 metre square area (each square is $1 \mathrm{~m}^{2}$ ).

Table 1: Estimated Coverage

\begin{tabular}{|l|l|}
\hline Plant/Life/Objects & Area coverage: Estimate $\left.\mathbf{( m}^{2}\right)$ \\
\hline Spear Grass & 13 \\
\hline Termite Nest & 2 \\
\hline Tree - Thay Palathi (Corkwood) & 9 (including branch coverage) \\
\hline Dead tree & 1 \\
\hline Eucalyptus (Bloodwood) & 34 (including branch coverage) \\
\hline Rock & 1 \\
\hline
\end{tabular}

Source: Student A 
The collected data provided the opportunity to develop Fermi investigation skills. Further demonstrations of understanding of the place can be found in the comments of Student A, presenting a biological perspective by suggesting that:

The conditions on the flat hill top make it an environment more suitable for resistant plants to grow. It would always be windy, which would blow away the unprotected soil, revealing more rock than dirt. The area is a flat hill top; the rains would wash away the soil downhill. Plants are scarce and there would not be much shade for more variety of plants to grow as the leaves would be hot and dry from the sun without shade. We even found that younger plants would have bigger leaves to create more shade and to catch rain. One type of eucalyptus grows in this area, Corkwood trees and lots of spear grass. These trees have rough bark that protects them from bush fires. (Student A)

\section{A glimpse of the paleo world: uncovering history}

On the walk back down the hill, travelling through a cutting, the upper sedimentary rock changed to white limestone. Investigations of the 'white rock' revealed brachiopod fossils and questions about how they got into the rock ensued. Under a tree half way down the hill, the world of millions of years ago unfolded, with the realisation that the hill and the surrounding flood plains were previously under the sea and most likely comprised a coral reef. The geology of this area was laid down under the shallow sea of the Carboniferous Period (Ahmad \& Munson, 2013).

This was a western science story based on science evidence from a flat top hill towering above the flood plains. The preservice teachers had no cultural stories of such geological changes, but there were stories of oil and gas exploration on their ancestral lands, including their clan Elders' displeasure about these activities. They went to the Elders to find stories, but there were none other than creation stories, which they did not give permission to write. Nonetheless, the lecturer promoted the space for B-W crossing of borders by the reconceptualisation of aspects of the Australian Science curriculum. Recontextualisation involved the legitimisation of Indigenous knowledge of place. B-W used preservice teacher and community meanings related to their local context of place together with western science, through the pedagogic device.

\section{The Cycad forest}

The comparison site, Gas Plant Road Cycad (Macrozamia sp.) forest, produced data and the opportunity to demonstrate Indigenous knowledge of the plants, different soil and their learned knowledge and skills of quadrat survey and estimation. After mapping a $100 \mathrm{~m}^{2}$ quadrat, the students used Google maps to find a satellite image for the Gas Plant Road and the surrounding area to estimate the total area. Then the students estimated how many cycad trees were in the study area. Figure 2 provides a representation of the Cycad forest area. The area was calculated by using estimated shape as a rectangle and a triangle. 
Figure 2: Cycad forest.

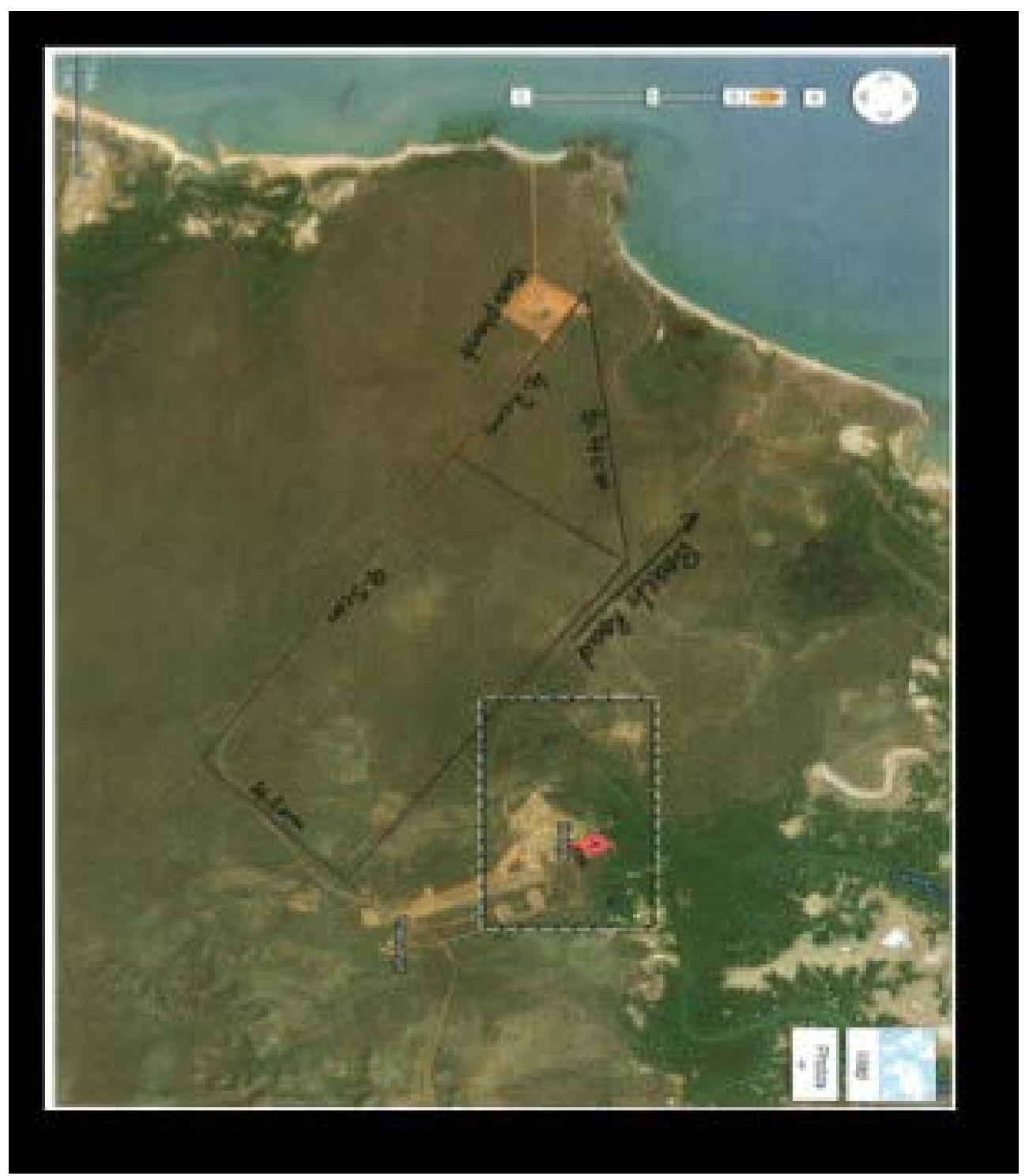

Source: Google Maps

The area of the Cycad forest was calculated from the estimate data and found to be approximately 12 $\mathrm{km}^{2}$. The next step involved using cycad tree density from the quadrat study to calculate the estimated number of Macrozamia sp., which was 12 million. So, what of the plan to dig them up and sell them in Darwin? All the students said "No", as the Cycad forest had specific cultural significance to both males and females of the community and should be left untouched.

\section{Concept mapping of Both-Ways knowledge}

The following concept maps present another example of a $B-W$ place-based science education initiative that situates Indigenous and western science knowledge traditions together as official curriculum science knowledge of a unit. This section presents outcomes of the preservice teachers' recontextualisations of the science curriculum content that is required in the accredited university course materials. The outcomes are presented as concept maps. The concept maps used in the context of this study demonstrate Indigenous preservice teachers' emergent understanding of Indigenous place-based knowledge and its place in the official curriculum. They also demonstrate the integration of Indigenous and western knowledge, which is a consequence of using the B-W approach. 


\section{Rubbish planning}

The student cohort, seven preservice teachers from an island community in the NT, decided that it would be important to focus on a local community problem to develop a teaching unit. They decided to ask their friends and relations about the community problem of rubbish, since this was a significant concern to them because rubbish lay everywhere in the community. The preservice teachers wanted the school and their students to be involved in solving this problem. The concept map, Rubbish Planning (Figure 3 ), presents the final representation of the group's plan. This map presents a border crossing object developed by the preservice teachers for the community. It presents mathematics in a meaningful and relevant context, while linking to music, art and dance/drama. This plan was implemented across their classes in the school.

Figure 3: Rubbish planning

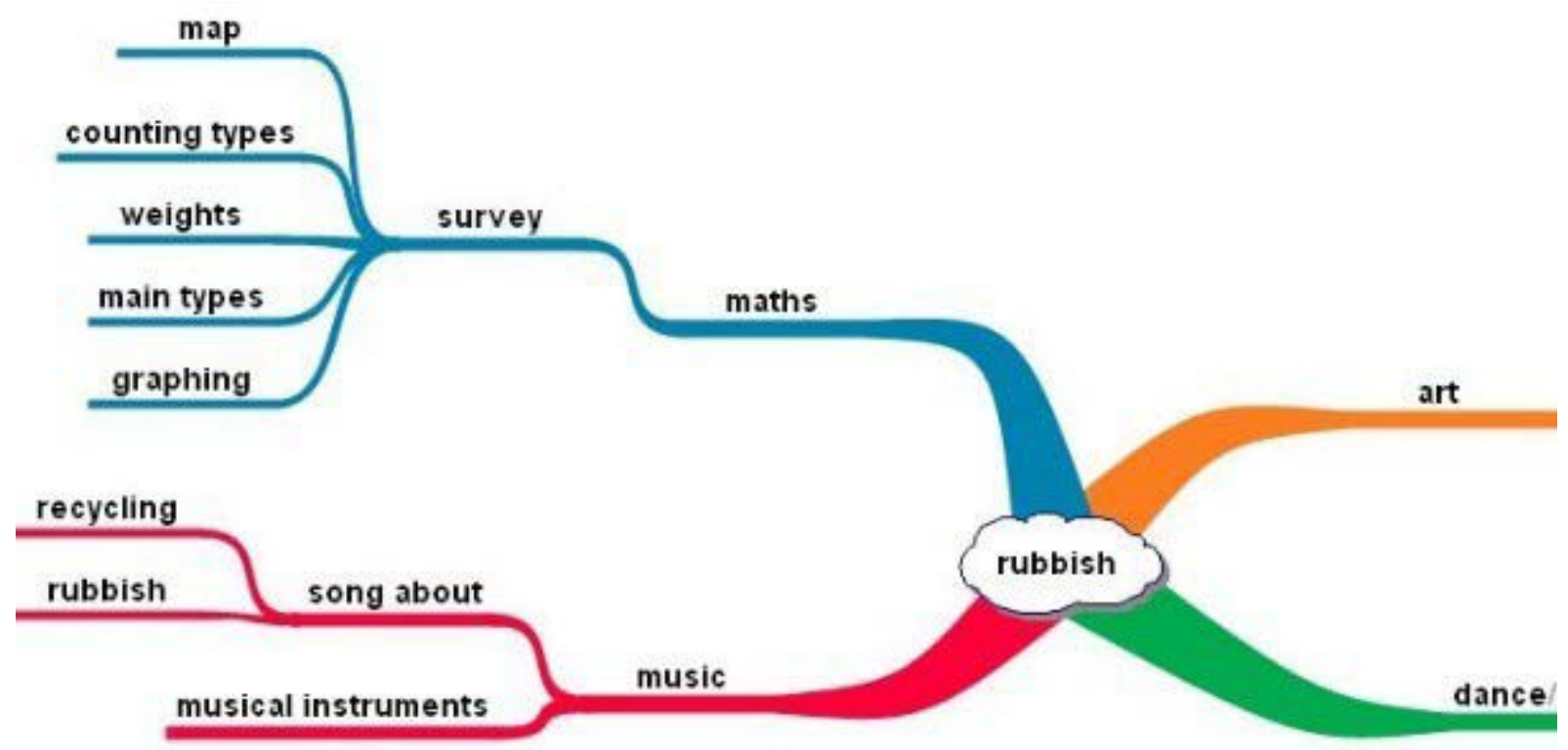

Source: Preservice teachers in NT island community

\section{Solar science}

The next concept map, Solar Science Knowledge, was developed by a preservice teacher student cohort from a freshwater community south-west of Darwin. The activity with these students was to design, construct and test a solar device. Having completed this task, the students were then asked to collaboratively develop a concept map to demonstrate the solar knowledge that they thought important in teaching solar concepts to their students. Figure 4 presents science as the central idea, and the preservice teachers' conceptions of the necessary knowledge. 
Figure 4: Solar science knowledge

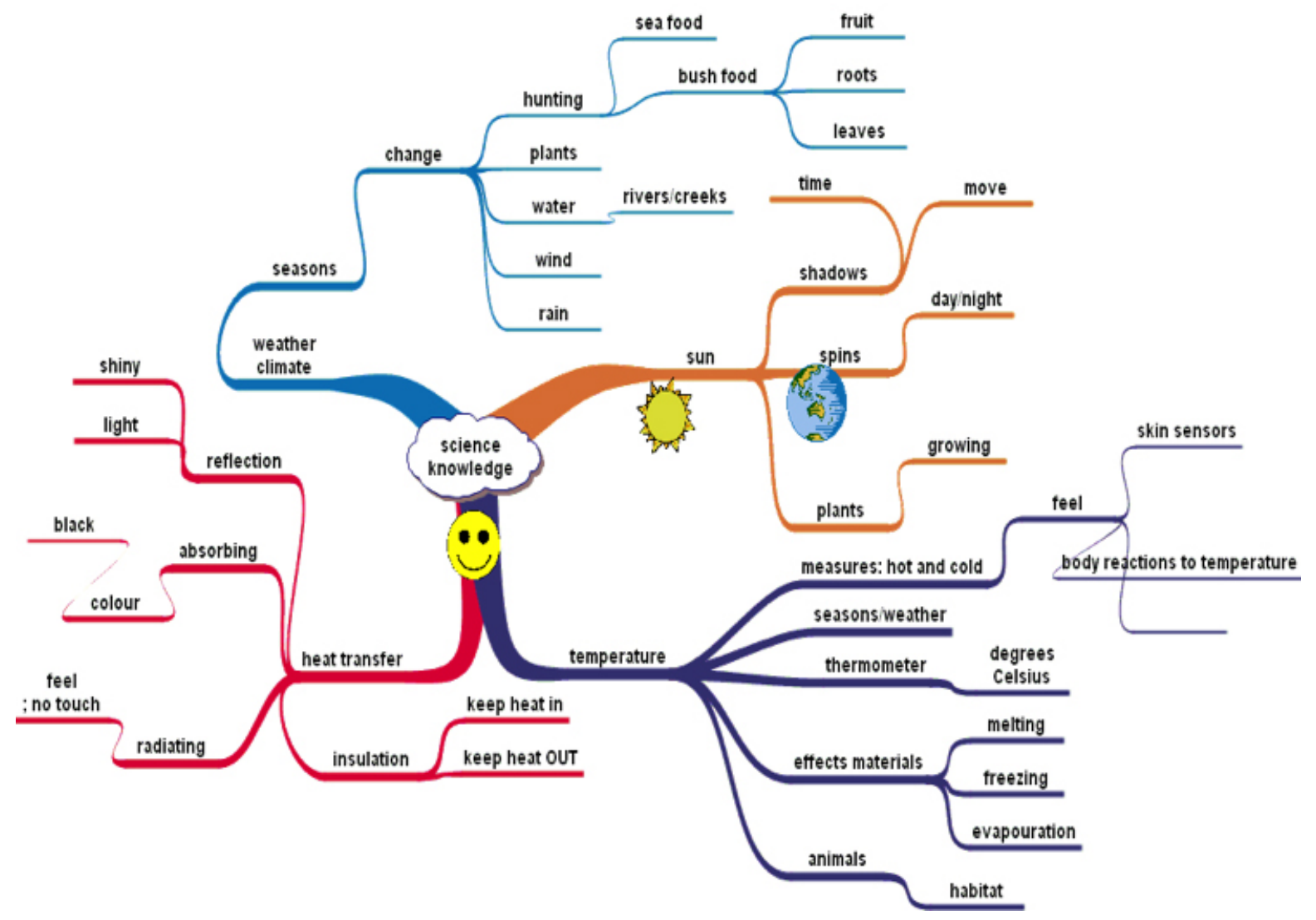

Source: Preservice teachers in freshwater community

The Solar Science Knowledge concept map demonstrates the official knowledge from the curriculum, but more importantly brings to the fore Indigenous knowledge of the land as a valuable knowledge component to the concept of solar. The inclusion of seasons, change, animals and plants represents a border-crossing reconceptualisation event that incorporates what is important to school science education in their community.

\section{Exploring water}

The last two concept maps (Figures 5 and 6) are placed in a desert community situated south-east of Alice Springs. The Indigenous preservice teacher students in this community decided that water was a problem for the whole community. They were planning to use water exploration as the place-based context for their teaching of science. The Exploring Water map (Figure 5) presents water as an inquiry with the central question: 'How do I know?' and it also includes the associated ideas for investigating this question.

The investigations presented in this concept map are from the preservice teachers' everyday experiences. There is a clear link with their everyday observations. The daily activities within their local community provide the context and generate relevant topics for investigations in science and mathematics. The properties, the modelling of water as particles, and the "holding hands" role play were part of the Explore - Explain phase of their learning within the science unit. 
Figure 5: Exploring water

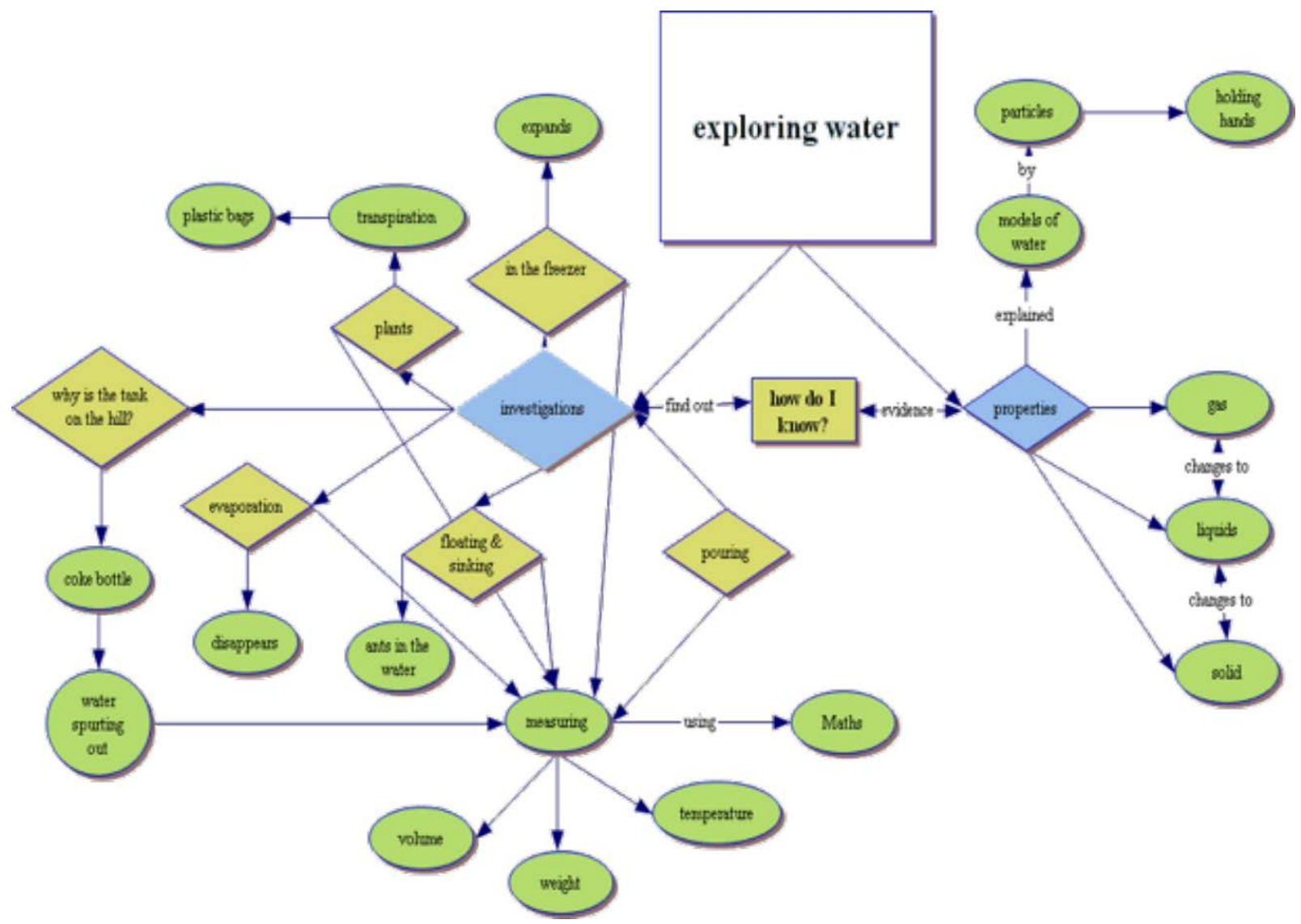

Source: Preservice teachers in desert community near Alice Springs.

\section{Engage phase}

The next concept map (Figure 6) presents preservice teachers concepts for the engage phase of the $5 E$ 's pedagogical approach (Bybee, 2009). The map uses place as a resource to engage in the topic of water. In this map, there is recognition of local issues, such as where you live, and when the water runs out. The preservice teacher students who developed this map demonstrated Indigenous knowledge from the outside (classroom) in the 'sources of water' branch. 
Figure 6: Engage phase

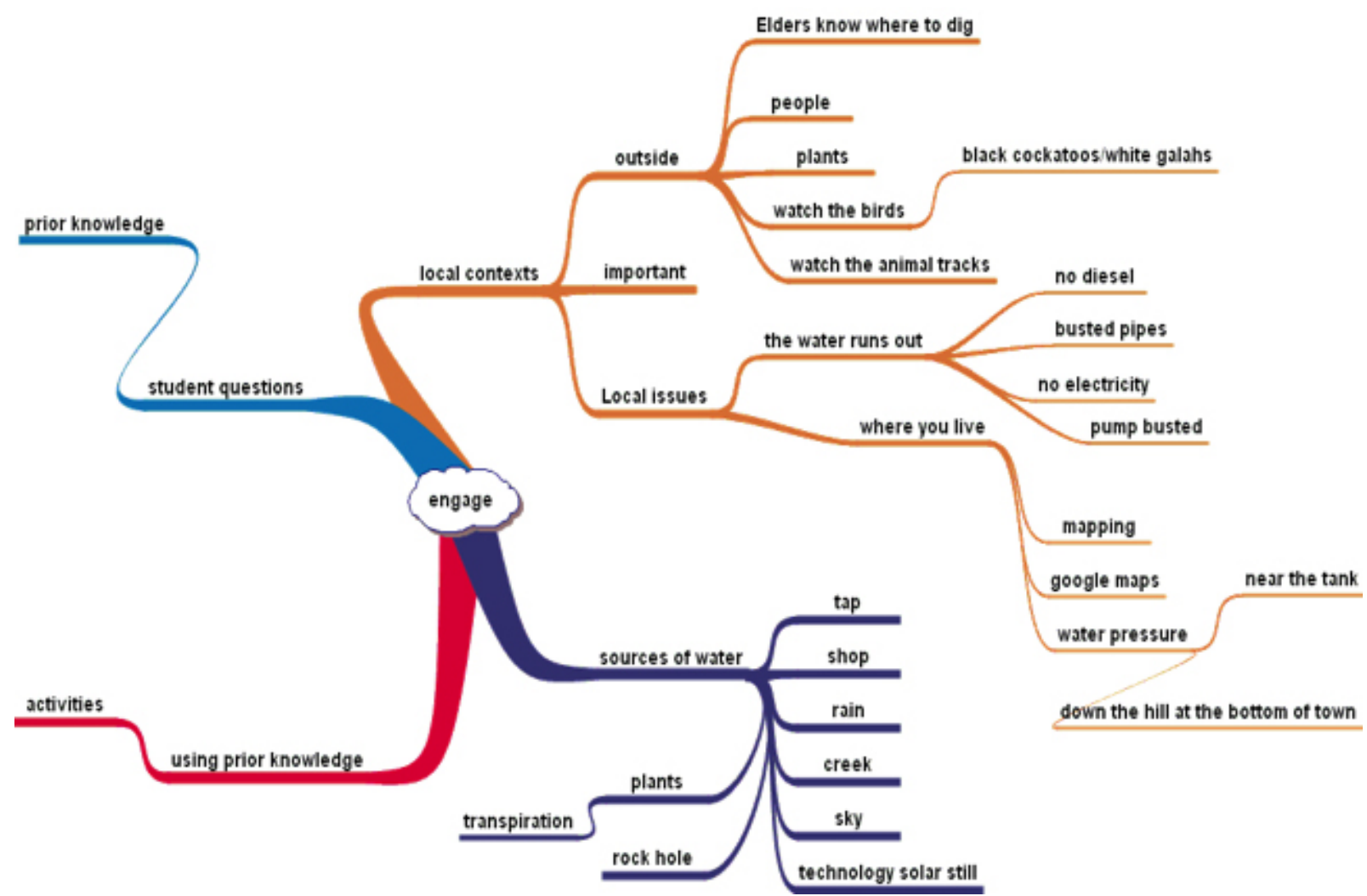

Source: Preservice teachers in desert community near Alice Springs.

\section{Discussion}

Pedagogical reconceptualisation discourse by the preservice teachers has been a generative border crossing with "ongoing creation and re-creation of the webs association" (Davis, Sumara, \& Luce- Kapler, 2015, p.81). This reconceptualisation requires a pedagogical approach that encourages conscious re-working of the schemas of the official school curriculum knowledge. This re-structuring of official knowledge develops new personal, collective and culturally constructed meanings (Bernstein, 2000).

These meanings, as demonstrated in the above examples, redistribute the knowledge and practice of what counts as valid knowledge and practice in school science. The B-W examples above are fortified by the construct of inclusion in which both Indigenous and western knowledge appear in the curriculum. What has emerged in the B-W approach is a new official curriculum constituted in a place- based pedagogical discourse that reconceptualises and recontextualises what counts as valid knowledge and pedagogical practice.

School science on the Tiwi Islands was re-contextualised in a B-W approach to provide a border crossing that connected the Indigenous and non-Indigenous worlds in a shared knowledge, understanding and language. The example with the yingwati or bush honey, demonstrated how a place-based B-W approach of curriculum recontextualisation operated in this community context. The concept maps from Indigenous communities (Figures 3-6) provided evidence that preservice teacher students were able to apply internal models of curriculum to blur the borders between Indigenous and non-Indigenous science. These pedagogic devices, which were externalised through visualisations and webs of association, highlight connections in the individual and collective understandings of the official curriculum knowledge. We consider that these are good examples of reconceptualisation discourse.

For lecturers, the Growing Our Own program provided an opportunity to embed a uniquely Australian science perspective into the science curriculum. Our examples present a pedagogical discourse that 
has developed classroom focused activities, which ensure that Indigenous cultural and school scientific integrity are upheld. The classroom activities validate preservice teachers' knowledge as part of the Australian science curriculum through a B-W place-based recontextualisation. For the preservice teachers, their local place is intended to enrich and bring to life the content descriptors of the western curriculum.

\section{Conclusion}

For Indigenous preservice teachers, the western academy often continues to impose a colonial view, language, and a foreign educative framework onto Indigenous peoples in science education, rather than using their local context. This paper provides examples of a pedagogical discourse in which Indigenous place-based knowledge and B-W school science are reconceptualised across the discipline boundary. The school science border is constructed through rules about knowledge and pedagogic practices based in the culture of western science. Similarly, the Indigenous place-based border is based on knowledge and pedagogic practices from Indigenous cultures. The Indigenous preservice teachers have demonstrated $\mathrm{B}-\mathrm{W}$ cultural border-crossing in the development of these border-crossing objects.

There is a crossing over at the curriculum border. This happens because Indigenous perspectives on place and their environment relate to including Indigenous knowledge in the curriculum, particularly in this case: the science curriculum (Michie, 2002, 2015). B-W teaching goes beyond knowledge and provides for a pedagogy that is "based on a tradition of real-life and problem-solving approaches to learning" (Ober \& Bat, 2007, p.80). This study offers insight into the pedagogic possibilities that emerge within a discourse that enables participation, engagement, and the valuing of Indigenous preservice teachers' knowledge. Local knowledge traditions, the place and local context are critical to lecturers in bridging cultures, and the B-W concept provides the framework for this to occur. 


\section{References}

Aikenhead, G. \& Michell, H. (2011). Bridging Cultures: Indigenous and Scientific Ways of Knowing Nature. Pearson Education, Ontario: Canada.

Ahmad, M. \& Munson, T. (2013). Geology and mineral resources of the Northern Territory. Northern Territory Geological Survey, Special Publication 5. Darwin: Northern Territory Government.

Australian Curriculum, Assessment and Reporting Authority. (2018). Preview of the Australian Curriculum, F-10 cross-curriculum priority refinement-Aboriginal and Torres Strait Islander histories and cultures in the Science learning area. Retrieved from https:// www.australiancurriculum.edu.au/f-10-curriculum/cross- curriculum-priorities/ aboriginal-and-torres-strait-islander-histories-and-cultures/

Barnhardt, R., \& Kawagley, A. O. (2008). Indigenous knowledge systems and education. Yearbook of the National Society for the Study of Education, 107(1), 223-241.

Batchelor Institute. (2007). Strategic plan. Batchelor: Batchelor Institute of Indigenous Tertiary Education. https://www.batchelor.edu.au/file_documents/Strategic_plan_2007V1.3.pdf

Bernstein, B. (1990). The structuring of pedagogic discourse. London: Routledge.

Bernstein, B. (2000). Pedagogy, Symbolic Control and Identity, revised edition, Oxford: Rowman and Littlefield.

Bhabha, H. (1994). The Location of Culture. Routledge: London.

Bybee, R. (2009). The BSCS 5E Instructional Model and 21st Century Skills. The Intersection of Science Education and the Development of 21st Century Skills. The National Academies Board on Science Education. Retrieved from https://sites.nationalacademies.org/cs/groups/dbassesite/documents/ webpage/dbasse_073327.pdf

Cajete, G. (2000). Native science: Natural laws of interdependence. Santa Fe, NM: Clear Light Publishers.

Connelly, F. M., \& Clandinin, D. J. (1990). Stories of experience and narrative enquiry. Educational Researcher, 19(5), 2-15.

Davis, B., Sumara, D., \& Luce-Kapler, R. (2015). Engaging Minds: Cultures of Education and Practice of Teaching. Routledge, New York.

Ezeife, A. N. (2003). The pervading influence of cultural border crossing and collateral learning on the learner of science and mathematics. Canadian Journal of Native Education, 27(2), 179-194.

Flinders University. (1996). General Information Folio 5: Appropriate terminology, Indigenous Australian Peoples. Retrieved from http://www.ipswich.qld.gov.au/documents/community/appropriate_ indigenous_terminoloy.pdf

Goodson, I. (2008). Investigating the teacher's life and work. Rotterdam: Sense Publishers.

Heinlein, R. (1961). Stranger in a Strange Land. New York: Penguin Random House.

Hyde, M., Carpenter, L., \& Conway, R. (Eds.). (2014). Diversity, inclusion and engagement (2nd ed.). South Melbourne, Victoria: Oxford University Press.

Linkson, M. (1999). Some issues in providing culturally appropriate science curriculum support for Indigenous students. Australian Science Teachers Journal, 45(1), 41-48.

McKinley, E. (2005). Locating the global: Culture, language and science education for Indigenous students. International Journal of Science Education, 27(2), 227-241. 
McConvell, P. (1982). Supporting the two-way school. In J. Bell (Ed.), Language planning for Australian Aboriginal languages (pp.60-76). Alice Springs: Institute for Aboriginal Development/Aboriginal Languages Association.

Michie, M. (2015). Science curricula and indigenous knowledge. Encyclopedia of Science Education, 871-877.

Michie, M. G. (2002). Why Indigenous science should be included in the school science curriculum. Australian Science Teachers' Journal, 48(2), 36-40.

Michie, M., \& Linkson, J. (1999, July). Interfacing Western science and Indigenous knowledge: A Northern Territory perspective. Proceedings of the 30th Australasian Science Education Research Association Conference. Rotorua, New Zealand.

Ober, R., \& Bat, M. (2007). Paper 1: Both-Ways: the philosophy. Ngoonjook: A Journal of Australian Indigenous Issues, 31, 64-86.

Peter-Koop, A. (2005) Fermi Problems in Primary Mathematics Classrooms: Fostering Children's Mathematical Modelling Processes [online]. Australian Primary Mathematics Classroom, 10(1), 4-8.

Rennie, L. (2006). The community's contribution to science learning: Making it count. Proceedings of the Australian Council for Educational Research (ACER) Research Conference 2006: Boosting Science Learning - what will it take? Canberra, ACT.

Sarra, C. (2007, June). The role of schools in shaping behaviour. Address presented at the Cape York Institute for Policy and Leadership.

Sarra, C. (2011). Strong and Smart - Towards a pedagogy for emancipation: Education for First Peoples. Abingdon, UK \& New York: Routledge.

Schott, J. (2005). Effective teaching strategies for Indigenous learners. Literacy Learning: the Middle Years, 13(2), 50-56.

Sutherland, D., \& Swayze, N. (2013). Evaluating Indigenous science education programs: Applying the Ininiwi- kiskanitamowin Indigenous Science Education Model to an informal education program. In R. Jorgenson, P. Sullivan, \& P. Grootenboer (Eds.), Pedagogies to enhance learning for Indigenous students: Evidence- based practice (pp. 175-191). doi:10.1007/978-981-4021-84-5_11

Webster, L., \& Mertova, P. (2007). Using narrative inquiry as a research method: an introduction to using critical event narrative analysis in research on teaching and learning. London: Routledge. 